\title{
Nomes próprios e artigos definidos no português brasileiro
}

\author{
Proper nouns and the definite article \\ in brazilian portuguese
}

Adeilson Pinheiro Sedrins

\begin{abstract}
Resumo
Neste artigo, apresentamos uma discussão sobre contextos sintáticos em que o nome próprio, no português brasileiro, pode ou não vir acompanhado por artigo definido. Há contextos em que a realização é obrigatória, quando o nome próprio é modificado, atuando como um nome comum, mas há contextos, como aqueles em que é modificado por construções apositivas, em que permanece com seu estatuto de nome próprio, podendo haver variação na realização do artigo. Ainda, há o contexto de inversão de predicado, em que o nome próprio, modificado, continua se referindo a uma única entidade no discurso e exige a realização do artigo definido.
\end{abstract}

Palavras-chave: Sintagma Nominal. Nomes próprios. Determinantes.

\section{Abstract}

This paper discusses the syntactic contexts in which Brazilian Portuguese proper nouns can optionally be headed by a definite article. When the proper noun is modified, acting as a common noun, the article is obligatorily licensed; on the other hand, in contexts such as those with appositives, in which the proper noun maintains its status, the occurrence of a definite article is optional. In addition, there is the context of predicate inversion, in which the proper noun is modified, maintains its status and is obligatorily licensed with an article.

Keywords: Noun phrase. Proper nouns. Determiners.

* Universidade Federal Rural de Pernambuco 


\section{Introdução}

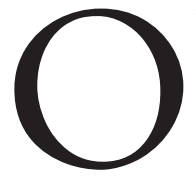

Português Brasileiro (PB) é uma língua que apresenta uma variação na realização do artigo definido diante de nomes próprios de pessoas ${ }^{1}$ (antropônimos), conforme pode ser verificado nos exemplos de (1) a $(3)^{2}$, em que o nome próprio João ocupa diferentes posições sintáticas:

(1) a. O João saiu cedo. João saiu cedo.

(2) a. Ela beijou o João. Ela beijou João.

(3) a. Ela gosta do João. A Maria gosta de João3.

Como a alternância entre a realização ou não do artigo definido diante de antropônimos parece, a princípio, não revelar alternância de leitura semântica,

1 Este trabalho está limitado ao estudo de nomes próprios de pessoas, antropônimos, e, por isso, não serão considerados para análise topônimos nem patronímicos.

2 É imperativo observar que outras línguas, como o italiano, o português clássico e o espanhol clássico, também apresentam a variação na realização do artigo definido diante de antropônimos.

3 Contextos em que o nome próprio é introduzido por uma preposição que pode se aglutinar ao artigo definido são contextos altamente condicionadores ao aparecimento obrigatório do artigo (cf. SILVA, 1998). Para falantes das regiões sul e sudeste do Brasil, dados como "Ela gosta de João" talvez soem mais estranho do que a construção com artigo: "Ela gosta do João". Isso porque as referidas regiões são as que mais produzem artigo definido diante de nomes próprios, conforme atestado em alguns estudos sociolinguísticos (cf. CALLOU; SILVA, 1997). 
A. P. SEDRINS Nomes próprios e artigos definidos no português brasileiro

é comum na literatura a sugestão de que se trata de um artigo expletivo, nos termos em que é colocado, por exemplo, em Longobardi (1994) 4

Embora a realização do artigo definido no PB seja um fenômeno atrelado a questões extralinguísticas, como, por exemplo, a comunidade de fala (cf. CALLOU; SILVA, 1997; SILVA, 1998; SEDRINS, 2013; entre outros), existem contextos em que a realização ou não do artigo definido implica diferentes leituras, não se configurando, portanto, como contextos de variação. Contextos em que o nome próprio é realizado com um modificador (adjetivo, sintagma preposicionado), por exemplo, parecem requerer a realização do artigo definido, conforme mostram (4) e (5):

(4) a. O João altão saiu primeiro.

b. *João altão saiu primeiro.

(5) a. O João de camisa vermelha é meu aluno.

b. `João de camisa vermelha é meu aluno.

Nos exemplos (4) e (5), o nome próprio é utilizado em situações em que se presume haver mais de um João, sendo necessário, nesse caso, individualizar o referente através de um modificador, que no caso de (4) é realizado pelo adjetivo altão e, em (5), pelo sintagma preposicionado de blusa vermelha. Em ambos os casos, a realização de um modificador restritivo para o nome próprio exige a realização do artigo definido. Isso acontece também em línguas em que geralmente o artigo não é licenciado com nomes próprios, como o inglês, conforme apresentado nos dados em (6):

(6) a. John has left/ ${ }^{\star}$ The John has left.

b. The tall John has left. / ${ }^{\star}$ Tall John has left.

Com base nessas considerações preliminares, este artigo tem como objetivo central descrever os contextos em que o artigo definido diante de nomes próprios se torna obrigatório, bem como os contextos em que a variação na realização pode se dar, buscando delinear um quadro descritivo sobre o que ocorre nos contextos em que o artigo definido é obrigatório no PB. Para isso, organizamos o texto da seguinte forma: na seção 1, discutimos a realização de nomes próprios no $\mathrm{PB}$ com outras categorias licenciadas à esquerda do nome: artigos, possessivos, demonstrativos, numerais e, ainda, quantificadores; na seção 2, discutimos a realização de nomes próprios em diferentes posições da sentença e, na seção 3, discutimos os contextos com construções apositivas, contrapondo ao contexto com sentença relativa restritiva, que torna obrigatória a realização

4 Castro (2006) atribui ao artigo definido realizado diante de possessivo pré-nominal e também diante de nomes próprios o estatuto de artigo expletivo, tanto para o português europeu, quanto

Revista Letras, para o PB.

Curitiba, UfPR,

n. 96, pp.239-254,

jul./dez. 2017.

ISSN 2236-0999

(versão eletrônica) 
do artigo; na seção 4, por sua vez, discutimos os contextos com inversão de predicado e a obrigatoriedade observada na realização do artigo para os contextos definidos; na seção 5, esboçamos um breve quadro explicativo para acomodar o padrão de realização de artigo definido diante de nome próprio nos contextos de inversão de predicado e de construção genitiva. Após a seção 5, apresentamos nossas considerações finais.

\section{Nomes próprios e determinantes}

Nomes próprios no PB podem vir acompanhados por diferentes determinantes (artigo definido, possessivo, demonstrativos), mas apenas nos contextos em que são realizados com o artigo definido temos uma leitura individualizada:

(7) a. (O) João não faz essas coisas ( ${ }^{\star}$ só se for outro João que faz).

b. Aquele João não faz essas coisas (só se for outro João que faz).

c. (O) Meu João não faz essas coisas (só se for outro João que faz).

As sentenças entre parênteses nos exemplos em (7) sugerem o contexto em que se presume uma situação em que há mais de um João. Observe-se que nos exemplos com o pronome demonstrativo (7b) e com o possessivo (7c) essa

242 leitura não individualizada para João é possível. Já para o exemplo em (7a), em que o nome próprio é realizado com artigo definido, a possibilidade de haver um outro João é descartada. Nesse caso, podemos observar que em (7b) e (7c) o demonstrativo e o possessivo atuam como elementos restritivos do nome próprio, isto é, de forma semelhante com que outros modificadores, como adjetivos e sintagmas preposicionados, atuam, conforme discutido na seção anterior, nos exemplos (4) e (5).

A presença do artigo em (7a) não implica uma leitura restritiva do nome; o nome próprio, por si só, garante uma leitura em que João se refere a um único indivíduo no domínio discursivo. Em (7a), então, o artigo definido, que pode ser omitido, parece atuar como um artigo expletivo, nos termos de Longobardi (1994) e Castro (2006), isto é, sem nenhum acréscimo semântico para a construção. Conforme buscamos mostrar ao longo do artigo, é exatamente no contexto em que o nome próprio por si só denota um único indivíduo que podemos obter a variação na realização do artigo definido, sujeita a interferência de fatores sociolinguísticos.

Além de determinantes, como artigos definidos, demonstrativos e possessivos pré-nominais, os nomes próprios podem também vir acompanhados 
A. P. SEDRINS Nomes próprios e artigos definidos no português brasileiro de numerais, havendo diferentes leituras com a realização ou não do artigo definido, como apresentam os exemplos em (8):

(8) a. Dois Joãos saíram (não três).

b. Os dois Joãos saíram ("não três).

O nome próprio utilizado no plural comporta-se como um nome comum, não apresentando a propriedade de denotar um único indivíduo. Assim, o contraste de leitura entre (8a) e (8b) é o mesmo tipo de contraste que encontramos com sintagmas nominais ( $\mathrm{SNs}$ ) cujo núcleo é um nome comum, como apresenta (9):

(9) a. Dois meninos saíram (não três).

b. Os dois meninos saíram ("${ }^{\star}$ ão três).

Nos exemplos (8b) e (9b), o artigo definido atua conferindo definitude ao $\mathrm{SN}$, não sendo, portanto, em nenhum desses casos, um artigo expletivo.

Para finalizar esta seção, consideremos agora o nome próprio no uso em que Muller e Negrão (1989) denominaram de uso como "objeto-palavra”. As ocorrências de João em (10) ilustram esse tipo de contexto:

(10) a. Ele se chama João.

b. *Ele se chama o João.

(11) a. O nome João é lindo.

b. ${ }^{\star} \mathrm{O}$ nome o João é lindo.

Nos exemplos em (10) e (11), o nome próprio é utilizado não para se referir a um indivíduo, isto é, não é um uso referencial. O nome próprio é utilizado como uma "entidade linguística", referindo-se ao nome do indivíduo e não ao indivíduo. Nesses contextos, o artigo definido é bloqueado. Conforme Muller e Negrão observaram, o uso metalinguístico verificado para o nome próprio em (10) e (11) é o mesmo que para qualquer outra palavra, como mostra a sentença em (12):

(12) a. Gosto do som da palavra abacate.

(MULLER; NEGRÃO, 1989, p. 538, ex. 17)

Dessa forma, o artigo definido não é licenciado em contextos como os apresentados em (10) e (11) por não se tratar de contextos em que o nome próprio faz referência a um indivíduo único. Da mesma forma, quando quantificados,
Revista Letras,

Curitiba, UFPR, n. 96 , pp.239-254, jul./dez. 2017. ISSN 2236-0999 (versão eletrônica) 
nomes próprios deixam de se referir a um único indivíduo, podendo se referir a todos os indivíduos que possuem o mesmo nome:

(13) a. Todo João é inteligente.

Muller e Negrão (1989) observam ainda que, em contextos quantificados em que aparece o artigo definido, a interpretação do nome próprio é referencial, como mostra o exemplo (14) retirado das autoras:

(14) a. Toda a Rafaela tem seu amor.

A leitura possível para Rafaela no exemplo acima é aquela equivalente a "a Rafaela inteira tem seu fâ", conforme observaram as autoras. Note-se que, apesar de em (14) o nome próprio ser utilizado como referencial, apontando para um único indivíduo, o uso do artigo definido não é opcional. Caso o artigo fosse suprimido em (14), a leitura disponível seria aquela equivalente para João, em (13), ou seja, seria a leitura referente ao conjunto de indivíduos com o mesmo nome. Dessa forma, em (14), o artigo definido exerce uma função de especificação.

Resumindo esta seção, exploramos a interação de nomes próprios com determinantes e numerais no $\mathrm{PB}$, observando também contextos em que são utilizados metalinguisticamente (como palavra-objeto), no plural e com o quantificador todo. Em geral, observamos que apenas quando o nome próprio é utilizado com referência a um único indivíduo é que podemos ter a opcionalidade 244 de realização do artigo definido, este se comportando como um artigo expletivo. Demonstrativos, possessivos, numerais e o quantificador todos, quando realizados com nomes próprios, são utilizados em contextos em que há a possibilidade de haver outros indivíduos com o mesmo nome, ou seja, contextos nos quais os nomes próprios passam a configurar-se como nomes comuns. O uso como nome comum é também verificado para nomes próprios no plural.

Com demonstrativos e possessivos pré-nominais, garantimos uma leitura específica do nome próprio, num contexto em que pode haver mais de um indivíduo com o mesmo nome. No contexto de numeral e de quantificador, a presença do artigo definido deixa de ser opcional quando se quer individualizar o referente nomeado. Ademais, nos contextos em que os nomes próprios são utilizados metalinguisticamente, isto é, como "palavra-objeto", nenhum determinante é licenciado.

Nas seções seguintes, direcionamos a nossa discussão para os contextos de artigo definido + nome próprio, a fim de apresentar um quadro descritivo sobre os contextos em que a opcionalidade do artigo é permitida e aqueles em que isso não ocorre. 
A. P. SEDRINS

Nomes próprios e artigos definidos

no português brasileiro

\section{Contextos de variação na realização do artigo definido diante de nome próprio}

Como vimos nas seções anteriores, apenas quando o nome próprio se refere a um indivíduo único é que podemos ter a opcionalidade na realização do artigo definido. Os exemplos em (15), abaixo, apresentam um nome próprio em diferentes funções sintáticas, referindo-se, em todos os exemplos, a um único indivíduo ${ }^{5}$ :

(15) a. (O) João beijou a menina.

b. A menina odeia (o) João.

c. A menina não gosta de/do João.

Nos exemplos acima, João aparece em diferentes posições sintáticas: em (15a), na posição de sujeito; em (15b), na posição de objeto direto; em (15c), na posição de objeto indireto. Em todos os casos, o artigo definido pode ou não ser realizado, sem que haja prejuízos semânticos. O mesmo ocorre quando o nome próprio é topicalizado:

a. (O) João, ele beijou a menina. ${ }^{6}$

Os exemplos em (15) e (16) correspondem a casos em que não há a possibilidade de haver outro indivíduo de mesmo nome na situação em que tais sentenças são proferidas, conforme mostram os exemplos em (17):

(17) a. (O) João beijou a menina (* e não outro João beijou a menina)

b. A menina beijou (o) João ( ${ }^{\star}$ e não outro João)

c. A menina gosta de/do João ( ${ }^{\star}$ e não de outro João)

d. (O) João, ele beijou a menina ( ${ }^{\star}$ e não outro João beijou)

Os exemplos de (15) a (17) sugerem, dessa forma, que a exigência da presença do artigo diante de nome próprio no $\mathrm{PB}$ não parece estar atrelada à função sintática da construção nominal nucleada por esse nome, tampouco atrelada ao fato de o nome estar em posição-A ou posição-A', já que ambos os usos (com artigo e sem artigo) são possíveis, independentemente da posição sintática em que o nome próprio é realizado.

5 Nos contextos apresentados em (15), a realização do artigo pode ser condicionada por fatores sociolinguísticos.

6 Aqui também encontramos um contexto em que a realização do artigo pode ser condicionada por fatores sociolinguísticos. Falantes de algumas comunidades do Nordeste tendem a aceitar a forma sem a realização do artigo, enquanto que falantes do Sudeste tendem a aceitar melhor a forma com a realização do artigo.
Revista Letras,

Curitiba, UFPR, n. 96, pp.239-254, jul./dez. 2017. ISSN 2236-0999 (versão eletrônica) 


\section{Nomes próprios em construções relativas e em contextos ampliados por aposto}

Outros contextos em que observamos a opcionalidade do artigo diante de nome próprio são os contextos em que os SNs são expandidos por uma relativa explicativa ou por um aposto, como mostram (18) e (19):

(18) a. O João, que sabe o que é bom, só bebe vinho importado ( ${ }^{\star}$ não outro João).

b. João, que sabe o que é bom, só bebe vinho importado (e não outro João).

(19) a. João, linguista renomado, faleceu este ano ( ${ }^{\star}$ e não outro João)

b. O João, linguista renomado, faleceu este ano ( ${ }^{\star}$ e não outro João)

Observe que, para as leituras dos exemplos em (18 a, b) e (19 a, b), João se refere a um único indivíduo, no universo em que a sentença é proferida, apesar de as construções apositivas - a sentença relativa em (18) e o aposto em (19) - atuarem na modificação do núcleo do SN. Nos casos em questão, a sentença relativa e o aposto não tornam obrigatória a realização de um determinante pleno. Podemos presumir que isso decorre do fato de que as construções apositivas são licenciadas fora do escopo do determinante que encabeça o Sintagma de Determinante $(\mathrm{SD})^{7}$, conforme defendido em um número robusto de análises, entre elas, as análises apresentadas em Fabb (1990), Kayne (1994), Bianchi (1999), Oliveira (2008), entre outros. Uma vez que não existe uma relação entre o determinante encabeçando João e as estruturas apositivas, não é de se esperar que a presença de um aposto implique ou não a realização de um determinante, isto é, nesses casos, a realização ou não de um determinante se dará por outras questões e não pela modificação implicada pelo aposto.

Ao considerar o caso das relativas restritivas que têm como núcleo nomes próprios, vemos que é obrigatória a presença do artigo definido, como mostra (20):

(20) a. O João que mora em Maceió viajou para São Paulo (e não o outro João).

b. *João que mora em Maceió viajou para São Paulo.

Assumindo que as restritivas entram em relação com o determinante que encabeça o SD - ver Bianchi (1999), Oliveira (2008) e outras obras ali citadas -, de alguma forma elas demandam a realização do determinante. A operação

7 Em boa parte deste artigo, referimo-nos às construções nominais como sintagmas nominais (SNs), por força do hábito e da tradição, que tem consagrado o uso desse termo. Nos casos em que queremos reforçar a ideia de uma estrutura nominal plena, um Sintagma de Determinante, em que o núcleo funcional D projeta, subcategorizando um SN, fazemos uso da etiqueta SD. 
A. P. SEDRINS

Nomes próprios e artigos definidos

no português brasileiro que insere a sentença restritiva faz com que o nome próprio se comporte como um nome comum, favorecendo, inclusive, a possibilidade de leitura em que no domínio discursivo haja outra entidade nomeada pelo mesmo nome. É o que pode ser depreendido de (20a). Como nome comum, a realização do artigo no contexto da sentença restritiva pode ser pensada como um mecanismo para garantir a todo o SD seu licenciamento como argumento, conforme defendido em Longobardi (1994) ${ }^{8}$.

\section{Nomes próprios em construções com inversão de predicado}

O último contexto que discutiremos é o de inversão de predicado, conforme postulado em den Dikken (2006). Em construções nominais com inversão de predicado, temos uma estrutura sintática realizada sob a forma $\mathrm{SN}_{1}+\mathrm{de}+\mathrm{SN}_{2}$, em que $\mathrm{SN}_{1}$ funciona como um predicado de $\mathrm{SN}_{2}$, tal como exemplificado em (21):
(21) a. O idiota do João
b. $\left[_{\mathrm{SN} 1} \mathrm{o}\right.$ idiota] de $\left[{ }_{\mathrm{SN} 2} \mathrm{o}\right.$ João]

Um fato interessante sobre essas construções no PB é o de que quando $\mathrm{SN}_{2}$ é nucleado por um nome próprio, a realização ou não do artigo definido diante deste implica uma diferença em termos de leitura disponível:

(22) a. A Maria beijou [o cachorro do João]

(23) a. A Maria beijou [o cachorro de João]

Enquanto em (22) temos uma estrutura ambígua, em (23), em que não há artigo definido diante de João, apenas uma leitura parece estar disponível. (22) poderia ser parafraseada como João tem um cachorro e Maria beijou esse cachorro (uma relação possuído-possuidor entre cachorro e João, respectivamente), como também poderia ser, numa diferente leitura, parafraseada como $A$ Maria beijou o João, que é um cachorro/sem-vergonha. Nessa última leitura, cachorro predica sobre João. Por sua vez, a leitura predicativa não está disponível em (23) e, nesse exemplo, a única leitura disponível é a da relação possuído-possuidor para o cachorro e João, respectivamente. Ou seja, a ausência do artigo definido diante de João, em (23), bloqueia uma leitura predicativa.

A fim de buscarmos compreender melhor a assimetria de leitura implicada pela ausência/presença do artigo definido nesses contextos, vamos explorar algumas propriedades sintáticas relacionadas às duas leituras que (22) apresenta.

8 A ideia de Longobardi (1994) a que nos remetemos aqui é a de que uma expressão nominal poderá ser tomada como um argumento se e somente se for introduzida por uma categoria D.
Revista Letras,

Curitiba, UFPR, n. 96, pp.239-254, jul./dez. 2017. ISSN 2236-0999 (versão eletrônica) 
O exemplo em (24) expressa claramente uma construção nominal com inversão de predicado, não havendo aí uma estrutura ambígua, como aquela apresentada em (22). Construções como a apresentada em (24) envolvem uma relação de predicação entre dois nomes contidos num DP, em que o 'sujeito' da predicação é realizado em forma de um sintagma preposicionado e o predicado é realizado pelo nominal que aparece na primeira posição. (25) é um exemplo de uma construção nominal em que o segundo elemento é uma construção genitiva:

(24) [ ${ }_{\mathrm{SN} 1}$ Umidiota] de [ ${ }_{\mathrm{SN} 2}$ um machista]

(25) $\quad\left[{ }_{\mathrm{SN} 1} \mathrm{O}\right.$ livro $] \mathrm{d}\left[\left[_{\mathrm{SN} 2}\right.\right.$ o Chomsky $]$

As duas construções acima são realizadas sob uma mesma forma sintática, isto é, apresentam, ambas, uma estrutura do tipo Det+N+de+Det+N. Apesar dessa semelhança entre as duas construções, (24) e (25) apresentam propriedades sintáticas distintas, entre essas, a possibilidade ou não de extração de $\mathrm{N}_{2}$ para fora do domínio nominal.

O teste da extração, que consiste em mover um constituinte de dentro de um domínio sintático, apresenta diferentes resultados quando aplicados a (24) e (25), ilustrados em (26) e (27):

(26) a. A Maria rasgou os livros do Chomsky.

b. De quem (que) a Maria rasgou os livros?

(27) a. A Maria beijou um idiota de um machista.

b. *De quem (que) a Maria beijou um idiota?

Como as possibilidades de extração estão condicionadas a restrições estruturais (CHOMSKY, 1986), o contraste entre (26) e (27) sugere que construções genitivas e construções com inversão de predicado apresentam configurações sintáticas distintas.

Retomando o contraste deleitura verificado entre (22) e (23), vamos recorrer à discussão apresentada em Foltran, Nóbrega e Oushiro (2016), doravante FNO. Os autores, observando o fenômeno da duplicação de determinantes em SNs no PB, observam que "é imprescindível que haja uma simetria entre o que está linearmente à esquerda e à direita do segmento $d e$ " (p. 179), em outras palavras, o mesmo determinante realizado com $\mathrm{N}_{1}$ deve ser realizado com $\mathrm{N}_{2}$. Os exemplos dos autores são retomados abaixo:

9 A utilização de artigo definido em lugar de indefinido em (24) deixaria a estrutura ainda mais fiel à apresentada em (25): o idiota do machista, como na sentença: o idiota do machista chegou. Mais adiante discutimos a realização de determinantes em construções com inversão de predicado. 
A. P. SEDRINS

Nomes próprios e artigos definidos

no português brasileiro
(28) a. artigos indefinidos:

b. artigos definidos:

c. nomes nus:

d. demonstrativos:

e.

(FNO, 2016, exemplos 10a - 10e, p. 179) [uma puta] de [uma festa]

[a vaca] de [a minha prima]

[merda] de [aula]

[esse burro] de [esse deputado]

[aquele merda] de [aquele motorista]

FNO observam ainda que a quebra da simetria observada em (28) poderia "gerar efeitos colaterais", ou causando uma mudança de leitura do SN, ou tornando a construção agramatical:

$(29)^{10}$ a. alguma puta de uma festa

b. (?)aquela puta de uma festa

c. (?)uma outra puta de uma festa

d. *a puta de uma festa

e. alguma vaca da minha prima (!)

f. aquela vaca da minha prima (= idêntico)

g. uma outra vaca da minha prima (!)

h. uma vaca da minha prima

(FNO, 2016, exemplos (11a-h), p. 180)

Observando os contextos de construções com múltiplos determinantes, envolvendo um nome próprio como o termo modificado, observamos as mesmas características observadas pelos autores, isto é, nos contextos definidos, a simetria na natureza dos termos em $\mathrm{SN}_{1}$ e $\mathrm{SN}_{2}$ deve ser observada, sob pena de não termos mais a leitura predicativa:

(30) a. [o cachorro] de [o João] - duas leituras disponíveis

b. [o cachorro] de [João] - uma leitura disponível

A leitura predicativa é assegurada: (a) nos contextos com múltiplos artigos indefinidos, em que o nome se comporta como um nome comum, e há simetria entre os artigos realizados (31); (b) em contextos definidos com múltiplos determinantes, com simetria entre o tipo de determinante que ocorre no SN (32); (c) em contextos definidos, em que é possível haver assimetria entre determinantes definidos (33):

(31) a. Um sacana de um João esteve aqui e levou tudo.

(32) a. O sacana do João esteve aqui e levou tudo.

b. Aquele sacana daquele João esteve aqui e levou tudo.

Revista Letras, 10 As observações entre parênteses também são de FNO (2016).

Curitiba, UfPR,

n. $96, \mathrm{pp} .239-254$,

jul./dez. 2017.

ISSN 2236-0999

(versão eletrônica) 
(33) a. Aquele sacana do João esteve aqui e levou tudo.

b. O sacana daquele João esteve aqui e levou tudo.

Nas construções predicativas, introduzidas por artigo indefinido, em que $\mathrm{N}_{2}$ é um nome próprio, caso não haja simetria entre os dois termos do SD, temos como resultado uma construção agramatical, como mostra (34):

(34) a. Um sacana de um João

b. ${ }^{\star}$ Um sacana do João

c. ${ }^{\star}$ Um sacana de João

Em contextos como o de (34), dessa forma, a obrigatoriedade de realização de um artigo indefinido diante do nome próprio se deve a uma necessidade de garantir a simetria entre os termos que compõem o SD, conforme observado por FNO, e não necessariamente por algum requerimento do nome próprio nesse tipo de construção. O que reforça isso é o fato de que nomes comuns apresentam as mesmas restrições de simetria, quando realizados em construções como a de (31), conforme pode ser visto nos exemplos em (29).

As sentenças em (33) mostram que, em contextos definidos, podemos ter uma assimetria entre os determinantes que encabeçam $\mathrm{SN}_{1}$ e $\mathrm{SN}_{2}$ : $\mathrm{SN}_{1}$ pode ser encabeçado por um pronome demonstrativo e $\mathrm{SN}_{2}$ por um artigo definido (33a), e o inverso também pode ocorrer (33b). FNO fazem essa observação para o exemplo em (29f), que retomamos dos autores. Se considerarmos a proposta de Raposo (1973 e 1998) de que existe apenas uma única forma $o$ no português, usada ora como determinante, ora como demonstrativo, a simetria, na verdade, é garantida nos exemplos apresentados em (33).

Outro fato curioso diz respeito às diferentes leituras que temos para as duas construções abaixo:

(35) a. O João idiota chegou.

b. O idiota do João chegou.

É possível utilizar a construção (35a) em um contexto em que há mais de um João e em que aquele que é considerado idiota chegou. No mesmo contexto, (35b) seria dificilmente produzida, no intuito de contrastar um João idiota com um outro João. Isso nos mostra que, em construção com inversão de predicado, apesar de modificado, o nome próprio continua se referindo a um único indivíduo no discurso, e a construção mantém a exigência da realização de um determinante. 
A. P. SEDRINS

Nomes próprios e artigos definidos

no português brasileiro

\section{Sobre as estruturas com inversão de predicado e estruturas genitivas}

Após a discussão sobre o comportamento de nomes próprios e sua relação com artigos definidos no PB, propomo-nos, nesta seção, a lançar algumas considerações sobre as derivações das construções com inversão de predicado e genitivas, a fim de compreender melhor o licenciamento de determinantes nesses dois contextos sintáticos distintos.

A questão primeira que nos colocamos é: por que em $O$ cachorro de João não podemos ter a leitura predicativa? A resposta, como vimos na seção anterior, parece ser a de que para garantir a leitura predicativa em construções com inversão de predicado, há de se observar uma simetria entre os termos $\mathrm{SN}_{1}$ e $\mathrm{SN}_{2}$. Isso nos leva a formular a questão de outra maneira: por que essa simetria tem que ser observada para garantir a leitura predicativa? Ainda: por que na leitura possuído-possuidor, ou seja, aquela proveniente de uma construção genitiva, o artigo diante do nome próprio, na posição $\mathrm{SN}_{2}$, não é obrigatório?

Recorrendo à proposta apresentada em Longobardi (1994), nomes próprios, quando utilizados como tais, ou seja, referindo-se a uma entidade intrinsecamente concebida como única no domínio do discurso, sofrem movimento da sua posição $\mathrm{N}$ para a posição $\mathrm{D}$. $\mathrm{O}$ autor ainda propõe, como um princípio, que a realização fonética de $\mathrm{D}$ é licenciada apenas se essa posição expressa um conteúdo semântico ou traços gramaticais, ou, ainda, como um último recurso.

No exemplo em (35b), que apresenta uma construção com inversão de predicado, temos a realização obrigatória do artigo definido diante do nome próprio, e o nome próprio continua se referindo a uma entidade única no domínio do discurso. Podemos pensar que a inserção do artigo se deve a um último recurso para satisfação de requerimentos gramaticais. Esse mesmo requerimento pode não se dar em construções genitivas, em que o nome próprio aparece na posição $\mathrm{SN}_{2}$.

Poderíamos assumir que numa construção genitiva temos, na verdade, dois SDs e cada um licencia foneticamente (ou não) seu determinante. Por outro lado, em construções com inversão de predicado, temos um único $\mathrm{SD}$, em que o núcleo D é licenciado fora do domínio em que são concatenados $\mathrm{N}_{1}$ e $\mathrm{N}_{2}$, como sugere den Dikken (2006), conforme passamos a discutir.

Uma vez admitindo diferentes estruturas para construção genitiva e construção com inversão de predicado, poderíamos explicar os contrastes de realização do artigo definido da seguinte forma: (i) para o caso da construção genitiva, com a leitura de possuído-possuidor, João pode tanto ser alçado para $\mathrm{D}$, ainda internamente a $\mathrm{SD}_{2}$, ocorrendo, então, sem artigo ${ }_{\mathrm{DP} 1}[\mathrm{o}$ [cachorro] de $\left.\left[{ }_{\mathrm{DP} 2}\left[\mathrm{D}_{\mathrm{D}} \mathrm{João}_{\mathrm{i}}\left[\mathrm{Ni}_{\mathrm{i}}\right]\right]\right]\right]$, ou, em último caso, ocorrendo com artigo, que preenche a posição D: $\left[_{\mathrm{DP} 1} \mathrm{o}\right.$ [cachorro] d $\left[{ }_{\mathrm{DP} 2}[\mathrm{D} \mathrm{o}[\mathrm{N}\right.$ João $\left.\left.]]\right]\right]$.
Revista Letras,

Curitiba, UFPR, n. 96, pp.239-254, jul./dez. 2017. ISSN 2236-0999 (versão eletrônica) 
Para a construção com inversão de predicado, a proposta esboçada em den Dikken (2006) é a de que $\mathrm{SN}_{1}$ e $\mathrm{SN}_{2}$ são estruturas menores que um SD -- basicamente são estruturas NumP -- e o determinante que aparece entre a preposição e $\mathrm{SN}_{2}$ é um determinante espúrio. $\mathrm{Na}$ análise do autor, esse determinante que ocorre diante de $\mathrm{SN}_{2}$ não forma com este um constituinte, sendo, na verdade, a própria realização do núcleo do RELATOR, categoria responsável por estabelecer a relação entre o predicado e o sujeito da small clause. Nesse sentido, a obrigatoriedade da realização do artigo diante de $\mathrm{SN}_{2}$, quando este é nucleado por um nome próprio, numa construção com inversão de predicado, não é um requerimento do nome próprio em si, mas da categoria que estabelece as relações de predicação entre $\mathrm{SN}_{1}$ e $\mathrm{SN}_{2}$. A estrutura sintática seria a seguinte: $\left[_{\mathrm{SD}} \mathrm{O}\left[_{\mathrm{RP}}\left[_{\mathrm{SN} 1}\right.\right.\right.$ cachorro] $\left[_{\text {link+relator }}\right.$ do [ [ ${ }_{\mathrm{SN} 2}$ João $\left.\left.]\right]\right]$.

\section{Considerações finais}

A variação na ocorrência ou não de artigos definidos diante de nomes próprios no português é um fenômeno já atestado por um número extensivo de trabalhos, muitos deles dedicados a uma descrição sociolinguística. Neste artigo, procuramos descrever as ocorrências de artigos definidos diante de nomes próprios, quando este item se torna obrigatório, sem que o nome deixe de funcionar como um nome próprio, ou seja, sem que deixe de denotar uma entidade única no domínio discursivo.

Nesse sentido, procuramos estabelecer os contextos em que o nome próprio, funcionando como tal, exige a presença de um artigo no $\mathrm{PB}$. O contexto a que chegamos foi o de inversão de predicado, quando o SN é de natureza definida. Nesse contexto, apesar de haver um modificador atuando sobre o nome próprio, como em O cachorro do João (cachorro = sem-vergonha), continuamos com a referência a um único indivíduo no domínio discursivo, não sendo possível a utilização desse tipo de construção em um contexto no qual seja inferida a presença de outro indivíduo com o mesmo nome.

Os demais contextos que verificamos, em que a presença do artigo definido é obrigatória diante do nome próprio, são contextos em que esse nome passa a se comportar como um nome comum. A obrigatoriedade do determinante, nesse caso, pode ser atribuída à necessidade de todo o DP ser interpretado em posição argumental, nas linhas do que propõe Longobardi (1994). 
A. P. SEDRINS

Nomes próprios $e$ artigos definidos no português brasileiro
Referências

BIANCHI, V. Consequences of antisymmetry: headed relative clauses. Berlin: Mouton de Gruyter, 1999. 357 p.

CALLOU, D.; SILVA, G. M. O. e. O uso do artigo definido em contextos específicos. In: HORA, D. da (Org.). Diversidade Linguística no Brasil. João Pessoa: Idéia, 1997. pp. 11-27.

CASTRO, A. On possessives in Portuguese. Tese de Doutorado -- Universidade Nova de Lisboa, Lisboa, 2006.

CHOMSKY, N. Barriers. MIT Press: Cambridge, 1986.

DEN DIKKEN, M. Relators and Linkers: the syntax of predication, predicate inversion and copulas. MIT Press: Cambridge, 2006.

FABB, N. The Difference between English Restrictive and Appositive Clauses. Journal of Linguistics, Cambridge, v. 26, p. 57-77, 1990.

FOLTRAN, M. J. G. D.; NÓBREGA, V. A.; OUSHIRO, L. Múltiplos determinantes em sintagmas nominais definidos e indefinidos do português brasileiro. In: PILATI, E. N. S. (Org.). Temas em Teoria Gerativa: Homenagem a Lucia Lobato. 1 ed. Curitiba: Blanche, 2016. p. 171-184.

KAYNE, R. S. The Antisymmetry of Syntax. Cambridge: The MIT Press, 1994.

LONGOBARDI, G. Reference and proper names: a theory of movement in syntax and LF. Linguistic Inquiry, Cambridge, v.25, p.609-665, 1994.

MULLER, A. L.; NEGRÃO, E. V. O uso do artigo definido antes do nome próprio em português: uma análise semântica. Estudos Linguísticos Anais de Seminários do Gel, São Paulo, v. XVII, p. 530-540, 1989.

OLIVEIRA, A. S. C. L de. As sentenças relativas em português brasileiro: aspectos sintáticos e fatos de aquisição. Tese de doutorado -- Unicamp, Campinas, 2008.

RAPOSO, E. P. Sobre a forma $o$ em português. Boletim de filologia XXII, Lisboa, p. 361-415, 1973.

Some observations on the pronominal system of Portuguese. Catalan working papers in linguistics, Barcelona, v. 6, p. 59-93, 1998.

SEDRINS, A. P. O artigo definido no português brasileiro em contextos de antropônimos e de possessivos pré-nominais. In: MOURA. M. D.; SIBALDO, M. A. (Org.). Para a história do português brasileiro: sintaxe comparativa entre o português brasileiro e línguas crioulas de base lexical portuguesa. v. III, tomo 4. Edufal: Maceió, 2013. p. 133-149.
Revista Letras,

Curitiba, UFPR, n. 96, pp.239-254, jul./dez. 2017. ISSN 2236-0999 (versão eletrônica) 
SILVA, G. M. O. e. Emprego do artigo diante de possessivo e de patronímico: resultados sociais. In: SILVA, G. M. de O.; SCHERRE, M. M. P. (Org.).

Padrões sociolinguísticos: análise de fenômenos variáveis do português falado na cidade do Rio de Janeiro. Rio de Janeiro: Tempo Brasileiro, 1998. pp.265-281.

Submetido em: 18-01-2017

Aceito em: 05-05-2017 